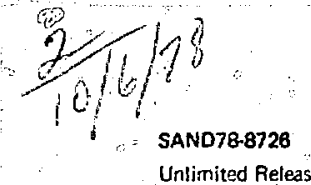

Untimited Release

Rayleigh Temperature Frofiles in a Hydrogen Diffusion Flame

J. R. Smöth

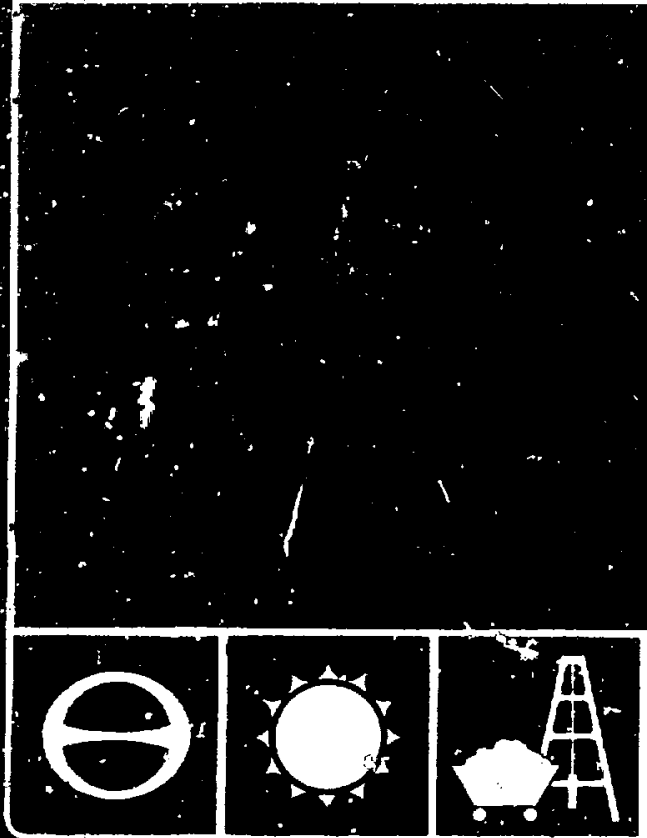
energy report
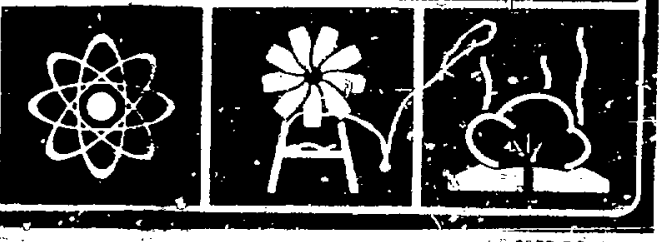


\title{
RAYLEIGH TEMPERATURE PROFILES IN A HYDROGEN DIFFUSION FLAME*
}

\author{
J. R. Smith \\ Sandia l.aboratories \\ Livermore, California 94550
}

\begin{abstract}
Rayleigh scattering from a hydrogen-air laminar jet diffusion flame in combination with a numerical model of the flame has been used to determine temperature profiles. The model predictions of species concentration are used to calculate a mean Rayleigh cross-section which is used to relate the Rayleigh scattered intensity to temperature. Using an argon ion laser producing $? .5$ watts at $488 \mathrm{~nm}$ and an optical multichannel anaiyzer (OMA), the scattered light was imaged into a spectrometer. The oMA was rotated 90 degrees to its normai orientation, allowing scans to be taken along the spectrometer exit silt. This resulted in a spatially resolved Rayleigh signal along the laser beam through the entire flame. Spatial resolution of $0.1 B \mathrm{~mm}$ on each of the 50 detectar elements with good signal-to-noise ratios was achieved even with integration times of only 0.03 second. Since the entire profile is made simultaneously, particulate perturbed profiles are easily recognized and discarded. Transverse profiles are presented to show fiame structure. Axial profiles are compared to radiation corrected thermocouple measurements.
\end{abstract}

\section{Introduction}

Detailed modeling of combustion processes offers the hope of understanding the complex interactions of fluid mechanical mixing and chemical reactions that occur in flames. Such modeling efforts require experimental data to quantify their accuracy and lend credibility to model extrapolations. At Sandia Livermore, Miller and Kee ${ }^{3}$ have recently modeled a laminar hydrogen-air diffusion flame which differed in some details from Raman scattering measurements of the flame as reported by Aeschliman and Cummings. 2 The Raman data indicated that the flame was significantly wider and hotter than the model predictions. These differences motivated an independent experimental study using Rayleigh scattering to determine temperature profiles. Although Rayleigh scattering has been used ${ }^{3}{ }^{-5}$ in $f 1 a m e s$ before, elastic scattering from particulates and differences in Rayleigh cross sections of both reactants and combustion products limit its utility. This experiment was performed in a clean room to reduce particulates to a minimum. The multiplex detector technique used also allows recognition of particulate signals and as will be discussed later, even restricts their influence on the total signal. The contributions to the Rayleigh signal by the various species in the flame are taken is.u account by using the model predictions of species concentration. It will be shown that there are relatively large regions in a laminar flame where uncertainties in species concentration have little effect on Rayleigh temperature measurements.

Theory

The differential cross section for Rayluigh scattering at 90 degrees from the incident light is given by

$$
\frac{d \sigma}{d n}=\frac{2 \pi^{2}(\mu-1)^{2}}{N_{0}^{2} \lambda^{4}}
$$

where $H$ is the index of refraction of the gas at STP, $N_{0}=2.69 \times 10^{19} \mathrm{~cm}^{-3}$ is a Loschmidt number, and $\lambda$ is the wavelength in $\mathrm{cm}, \star \star t$ The effective Rayleigh differential cross section of a gas mixture is the sum of the mole fraction weighted cross sections:

$$
\left(\frac{d o}{d n}\right)_{\text {eff }}=\sum_{i} x_{i}\left(\frac{d \sigma_{i}}{d \Omega}\right)
$$

Here the mole fraction, $x_{j}$ tern is taken from the numerical model, and is a function of both axial and radial position in the flame. In practice, only major species $\mathrm{H}_{2}, \mathrm{~N}_{2}, \mathrm{O}_{2}$, and $\left(\mathrm{H}^{\prime}\right)$ need be included in the sumation since radical concentrations are always small in the hydrogen air flame.

"This vork was supported by the US Department of Energy under Contract AT(29-1)789.

" Note that the use of equation (1) tacitly assumes that depolarization ratios are smajl, which is the case for the major species involved.

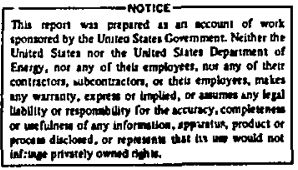


The Rayleigh scattered intensity is therefore

$$
I_{s}=C I N \Omega\left(\frac{d \sigma}{d \Omega}\right)_{e f f}
$$

where $C$ is a calibration constant of the collection optics, l the incident laser intensity, $N$ the molecular number density, $\Omega$ the solid angle of the collection optics, and $\&$ the length of laser beam imaged onto the detector. Since the effective differential cross section and number density are a function of location in the flame, the scattered intensity, $I_{s}$ is also a function of position. The ideal gas equation-of-state describes the relationship between the pressure, $P$ the number density and the absolute temperature, $T$

$$
\mathbf{P}=\frac{\mathrm{N}}{A_{\mathrm{D}}} \mathrm{RT}
$$

where $A_{0}$ is Avogadro's number and $\mathrm{R}$ is the universal gas constant. The static pressure is constant in a low velocity jet; thus the nunber density is inversely proportional to the temperature.

Solving equation (4) for the number density, substituting it into equation ( 3 ) and rearranging yields an explicit expression for temperature

$$
T=\frac{\operatorname{CI} \Omega \Omega}{I_{s}} P\left(\frac{A_{0}}{R}\right)\left(\frac{d \sigma}{d \Omega}\right)_{e f f}
$$

If the scatcered intensity, $I_{0}$ is measured at a known temperature, $T_{0}$ (for example, room temperature far from the flame) and the differential cross sections normalized by the ef. fective cross section at the known point, equation (5) may be simplified further to

$$
T(r, x)=\frac{T_{o}\left(\frac{d \sigma}{d n}(r, x)\right)_{\text {eff }}}{\left(\frac{I_{s}(r, x)}{I_{o}}\right)\left(\frac{d \sigma}{d \Omega}\right)_{0}}
$$

where the spatial dependence of the scaitered intensity and temperature have been included. The procedure for determining temperature in the flame is thus reduced to computing the effective differential Rayleigh cross section based on the species concentrations predicted by the numerical model and measuring the Rayleigh scattered light intensity for each point of interest relative to that of the unheated air well outside the flame.

\section{Experimental Arrangement and Procedure}

The burner to produce the flame was a straight, vertical tube of $6.35 \mathrm{~mm}$ inside diameter with the outer surface tapered to a narrow lip at the top. The hydrogen was regulated to a constant flow rate of $19 \mathrm{~cm}^{3} / \mathrm{sec}$ which yields a parabolic velocity profile at the tube outlet with a centerline velocity of approximately $600 \mathrm{~cm} / \mathrm{sec}$. The buxner was mounted on a precision traverse to allow accurate vertical adjustment of the axial distance, between the burner tip and the horizontal laser beam. The entige experiment was located in a down flow, clean room to miлimize the number of particulates in the air entrained by the flame. (As long as the plumbing was not disturbed, the hydrogen flow showed no indication of particulates.) The fans in the clean room were stopped for a few minutes before and during the time that measurements were taken. This allowed the flame to stabilize and yet entrain virtually particulate-free air.

The optical arrangement used is shown in Figure 1. A 7.5 watt, 488 nanometer laser beam was focused with a $500 \mathrm{~mm}$ focal length lens above the burner tip to give a long cylindrical scattering region. This configuration provides a beam of less than 0.25 mm diameter over a $75 \mathrm{~mm}$ length. Apertures and light traps were carefully placed to mininize scattered light due to sources outside the scattering vol me from entering the collection optics.

The collection optics were chosen to image the scattering volume into the entrance slit of a $3 / 4$ moter spectrometer. A dove prism was used to rotate the horizontal im? 2 of the scatticring volume to the vertical entrance sil. These optics demagnified the image of the volume by a factor of about seven. An Optical Multichannel AnalyzeriA (ONIA), Princeton Applied Research Model 1205D, was mounted at the exit plane of the spectromater to scan vertically. Thus a $0.18 \mathrm{~mm}$ length of the scatering volume was imaged onto each of the 512 channeis of the OMA for a total field of view of $92 \mathrm{~mm}$. It was necessary, however, to restrict the spectroneter entrance $s+i t$ height to $10 \mathrm{~mm}: 0$ inprove stray light rejection which resulted in a total field of view of about $74 \mathrm{~mm}$. The edges of two knife blades, 


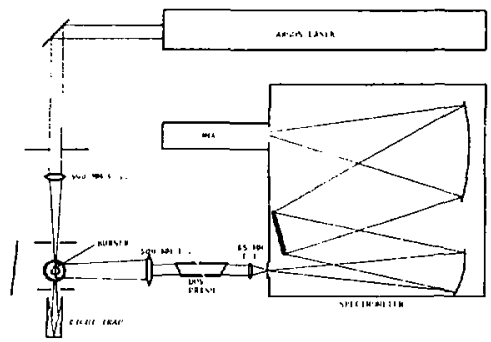

Fig. 1. Plan view of optical arrangement.

separated by a $40 \mathrm{~mm}$ spacer, were placed above the burner partially in the attenuated laser beam to give a scattered light signal from their location. In this manner the average width of the image on each channel $: 0.18 \mathrm{ma})$ was determined.

The spectrometer entrance slit width was $0.2 \mathrm{~mm}$, giving a spectral resolution of 0.2 nanometers. This resolution assures complete collection of the elastically scattered 1 ighe while rejecting the rotational Raman limes of the najor species. The spectrometer also rejected nost of the faint blue continuon of the hydrogen flane due to the reaction $\mathrm{H}+\mathrm{OH} \rightarrow \mathrm{H}_{2} \mathrm{O}+\mathrm{hu}$.

The spatial variation of the sensitivity of the optical system was about 20 percent in a smooth cosine-1ike distribution. The sensitivity variation was easily accounted for by norinalizing by the Rayleigh signal from room ait with the flame off. The Rayleigh signaI has recorded as an analog signal on is CRT display and on a digital printer. Although the andiog Jisplays are presented in the next section as typical data, actual conputation of teaperitures used the digital output. Coab signal-to-noise ratios ware achieved with the $1 / 30$ second siagle frame integration time of the ONA. Hovever, 3 second integration times fierc used to reduce the paision counting $s$ titistics uncertainty of the lowest signals to the one percent level. Since the saturation jevel of the $1205 \mathrm{~b}$ oNh is 750 counts and the Rayleigh signal from roon air was about 500 counts per channel (on a single frame), the signal from a particle passing through the scattering volume was "clipped" at the saturation count. This means that a particle can only contribute a few hundred counts to the approxinatedy 40,000 counts of the total integrated signal. Such a contribution is equivalent to less than $12 k$ even in the hottest part of the flame. It is unlikely that the sig. nal from mare than onc particle was ever present on a single channel due to the clean room conditions. Mlso a particle traveling at a vertical velocity of $100 \mathrm{~cm} / \mathrm{sec}$ would have a residence time of only 250 microseconds in the scattering volume. Therefore, it would never be seou for more than one Frame.

As was previously mentioned, there are large regions in a hydrogen-air diffusion flame wherc uncertainty in the species concentrations does not significantly affect the use of Rayleigh scatering to determine temperature. This statement can be appreciated by examination of Figure 2 which contains both the numerical model predictions of concentrations and the resultant effective Rayleigh cross section at an axial distance of 10 mm above the burner. Note that the effective cross section is still 90 persent of the air value at the reaction zone near the $6.5 \mathrm{ma}$ radius. Therefore, the region from the reaction zone outward requiles litele correction due to species concentration. One would expect a similar situation in all laminar diffusion flames. Along the centerline of the hydrogen-air flame relatively large corrections are necessary due to the small Rayleigh cross section of the hydrogen. Since vibrational Raran temperatire measurenents are difficult in air below $800 \mathrm{~K}$ due to snall first vibrational level populations, Rjyleigh scattering greatly complements such data.

\section{Resules}

Figure 3 shows the change in Rayleigh signal at several axial positions. These are analog profiles that have not been normalized by the optical system sensitivity. (Hence. the roll-off of the signal at large radii.) From equation (6) we expect a low signal to imply high temperature except in the center where the hydrogen reduces the signal.

The temperature profiles calculated fron the digital data at $x=10 \mathrm{~mm}$ and $\mathrm{x}=20 \mathrm{~mm}$ axial distance are presented in figures $t$ and 5 , respectively. Also included are the 


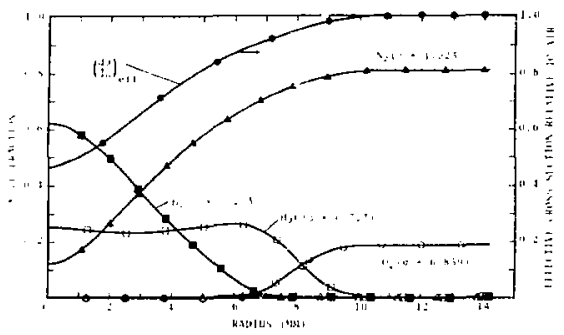

Fig. 2. Numerical model predictions of species concentrations and effective Rayleigh cross section at $x=10 \mathrm{~mm}$ above burner.

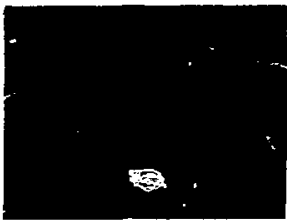

SFatial Sensitivity (No Flanc)

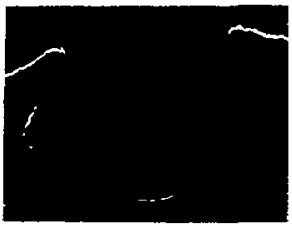

$x=\$ 0 \mathrm{~cm}$

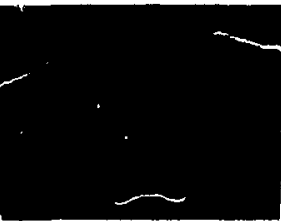

$x=10 \pi$

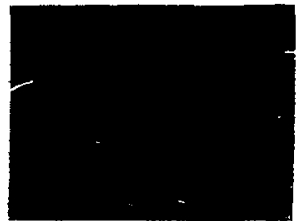

$x=20 \mathrm{~min}$

Fig. 3. Rayleigh signal radial profiles at setural axial positions above burner using an integration tine of 3 seconds.

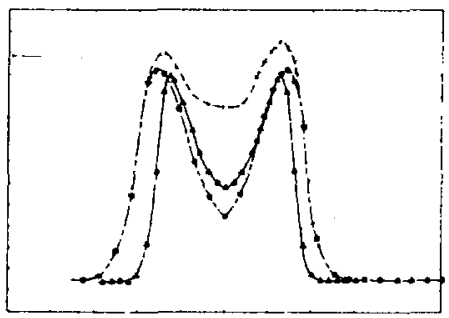

Fig. 4. Experimental and numerical moled temperature proliles at $x=10$ mm abue burner. 


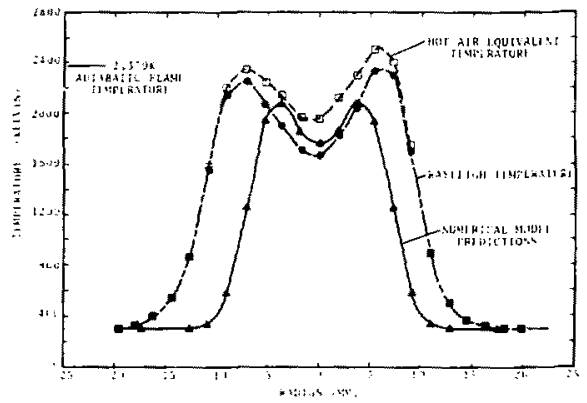

Fig. 5. Experimental and numerical notel tenperature profiles at $x=20$ mabove burner.

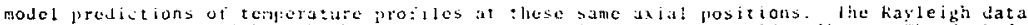

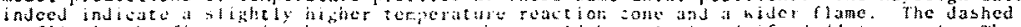

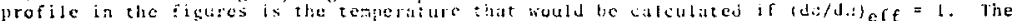

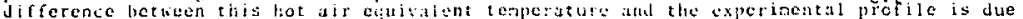
to ahe correction tor the afrecies voncent rations.

It was noticed fron the single lrame exposures that there was considerable flane "flicher" at less cian the jo jif franing rate. To visualizc this flicher, thirty consecutive profiles were overlayed on the ckT display as show in liture 6 . The width of the profile in the vertical direction corresponds to the deuree of flicker. Notite that this increases with height. Such an instability in iamanar liames has been noted beforo by Erant and Jones. " The flicher is apparently a fluid instability that is independent of botb Reynolds number and fuel used in a laminar flanc. As such, it contributes to the appearane that the flame is wider than a stable flane. it hould certuinly be misleading for long integration, such as the 120 second integration necessiry for the Raman data cited earlicr.
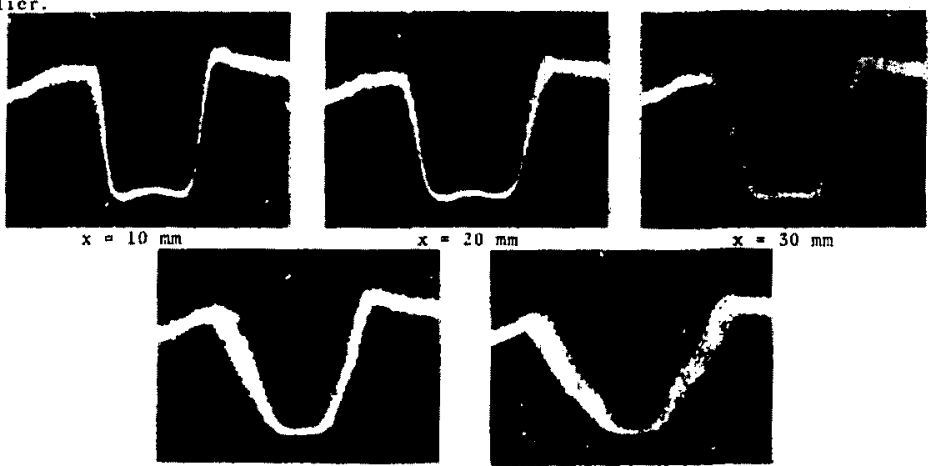

$=20 \mathrm{~mm}$

$x=30 m m$

$$
\therefore 40 \mathrm{~mm}
$$

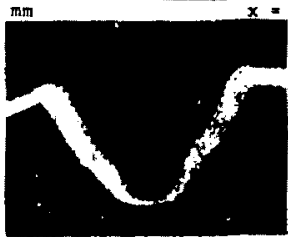

Fig. 6. Thicty sequential profites

$$
x=50 \mathrm{mat}
$$

integration time showing flame "flicker". 
The $x=20$ ma axial position profile in Figure 6 was taken about ten minutes after the clean roon fans had been off. It clearly shows how particulates are present. None of the temperature data were taken at such late times afte: fan shutdown.

Even accouncing for flame flicker by estimating its width from short time exposures, the Elane appears wider than the model predicts. This is shown in Fisure 7 where the model and experigental $1500 \mathrm{~K}$ isotherns are compared with "flicker" estinates included on the experimental data.

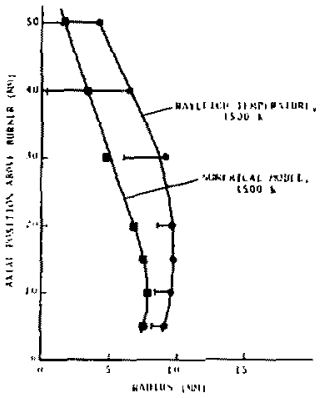

Fig. 7. Exporinental and numerical model flame shape along outer $1500 \mathrm{~K}$ isotherm. Bats on experimental lsotherm indicate magnitude of flane "flicker".

An axial temperature profile was constructed from the centerline data of the radial pro files. This data is compared with the model pjedictions in Figure 8 . The influence on the temperature value by $a=10$ percent variation in the hydrogen concentration is denoced by the vertical bars at the $x=10$ mo position where the axial hydrogen gradient was very large. The numbers at each point are the ffective relative differential cross section values used. Note that the experimental evidence indicates a slightly longer and hot ter flame than the model predicts.

Also included in Figure 8 are square symbols to represent axial temperatures obtained from radiation corrected thermocouple data. The thermocouple consisted of a 0.25 ma diamoter bead of platinum, platinum-13 percent rhodium coated with silica to reduce catalytic effects. Due to the extremely steep temperature gradients, it is probably not practical to ake radial profile thernocouple measurenents. Since the thermocouple radia tion correction consists of a heat transfer balance between the convective and radiative transport to the chermocouple bead, the species concentrations from the model had to be used in the convective terms. The maximum radiation correction was. $165 \mathrm{~K}$ a $x=35$ mm. because conduction along the thermocouple leads was not included in the correction and a high radial temperature gradient is present at the $x=5$ min position, the thermocouple indicaces a remperaturc above. the actual gas temperature.

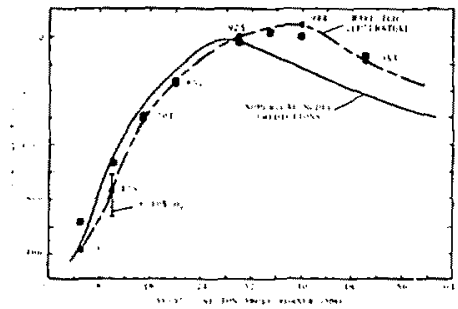

Fig. 8. Experimental and numerical model axial tcmperatures. Value of effective Rayleigh cross sections are indicated at each experimental point. Radiation corrected thernocouple measurenents shown by 


\section{Conclusions}

Rayleigh scattering has been used to determine temperatures in a laminar hydrogen-air flame. The relatively large Rayleigh scattering cross sections allowed short integration times which led to the discovery of flame oscillations. These oscillations partially account for the difference between the flame model and previously reported Raman temperature measurements. However, the Rayleigh temperature data indicate a slightly longer, wider, and hoter flame than the numerical model predicts.

\section{References}

1. Miller, J. A. and Kee, R. J., "Chemical Nonequilibrium Effects in Hydrogen-Air Laminar Jet Diffusion Flames," Journal of Physical Chenistry 81, p, $2534,1977$.

2. Aeschliman, D. Ind Cummings J Jr. Hpplication of Raman Scattering to the Study of a Hydrogen Laminar Diffusion Flame in Air," presented at the Optical Society Annual Meeting, Toronto, Canada, October 1977.

3. Robben, F., "Comparison of Density and Temperature Measurements Using Ranan Scattering and Rayleigh Scattering," Combustion Measurements in Jet Propulsion Systems, (ed. R. Goulard), Project SQUrD workshop Proceedings PU-KI-76, Purdüe University, p. 179, May 1975

4. Pitz, R. W. Cattolica, R. J., Robben, F., and Talbot, L., "Temperature and Density in a Hydrogen-Air Flame from Rayleigh Scattering," Combustion and F1ame 27, p. 313-320, 1976.

5. Cattolica, R. J., Robben, F., and Talbot, L., "The Interpretation of the Spectral Structure of Raylcigh Scattered Light from Combustion Gases, "AIAA 14 th Aerospace Seiences Neting, AlAd paper No. 76-31, January 1976.

6. Shardanand and prasad Rao, A. D., "Absolute Rayleigh Scattering Cross Sections of Gases and Freons of Stratospheric Interest in the Visible and UItraviolet Regions," NASA TND-8442 liallops Flight Center, Narch 1977.

7. Padley, P. J., "The Origin of the Blue Continuun in the Hydrogen Flame," Transactions of the Faraday Society, Vol. 56, p. 451-454, 1950 .

8. Grant, A. J. and Jones, J. M., "Low-Frequency Diffusion Flane Oscillations," Combustion and Flame 25, p. $153-160,1975$ 